\title{
Two new species of entobdelline skin parasites (Monogenea, Capsalidae) from the blotched fantail ray, Taeniura meyeni, in the Pacific Ocean, with comments on spermatophores and the male copulatory apparatus
}

\author{
Ian D. Whittington ${ }^{1,2^{*}}$ and Graham C. Kearn ${ }^{3}$ \\ ${ }^{1}$ Monogenean Research Laboratory, Parasitology Section, The South Australian Museum, North Terrace, Adelaide, \\ South Australia 5000, Australia; ${ }^{2}$ Marine Parasitology Laboratory, School of Earth and Environmental Sciences (DX 650418 ), \\ The University of Adelaide, North Terrace, Adelaide, South Australia 5005, Australia; \\ ${ }^{3}$ School of Biological Sciences, University of East Anglia, Norwich, Norfolk NR4 7TJ, UK
}

\begin{abstract}
We made a comparative anatomical study of entobdelline monogenean skin parasites from the blotched fantail ray, Taeniura meyeni $(=$ T. melanospila) from public aquaria and fish-holding facilities distributed widely across the western Pacific Ocean. These facilities were located in Australia (Mooloolaba, southern Queensland; Cairns, northern Queensland), Taiwan and Japan. The capture localities of the aquarium fishes are unknown to us, with the exception of the individual fish from northern Queensland which came from Sudbury Reef, a local inshore reef. Entobdellines from southern Queensland differed morphologically from those from northern Queensland and Taiwan and the 2 new monogenean species are described and named Neoentobdella garneri sp. nov. and $N$. taiwanensis sp. nov., respectively. We determined that an entobdelline collected by Dyer and co-workers from a ray identified as T. melanospila $(=T$. meyeni) from an aquarium in Okinawa, Japan and identified by them as Entobdella squamula (Heath, 1902) Johnston, 1929 was misidentified and is tentatively assigned to N. taiwanensis sp. nov. The male copulatory organ of each new species resembles a penis, but evidence that these organs are eversible like a cirrus is presented. Caution is advised in deciding whether the male copulatory organs of capsalids may function as a penis or as a cirrus and we suggest that possession of a penis versus a cirrus may not necessarily indicate wide evolutionary divergence. In N. garneri, spermatophores consist of a sausage-shaped capsule and a long hollow stalk. A spermatophore received from a donor is anchored in the vagina by means of the stalk, with the capsule protruding outside the body.
\end{abstract}

\section{Keywords}

Platyhelminthes, Monogenea, Entobdellinae, Neoentobdella, stingrays, Dasyatidae, spermatophores, penis, cirrus, functional morphology

\section{Introduction}

The blotched fantail ray, Taeniura meyeni Müller et Henle, 1841 (Dasyatidae), is widely distributed in the western Pacific Ocean and elsewhere (Last and Stevens 1994; Froese and Pauly 2008). This stingray is better known by the junior synonym T. melanospila Bleeker, 1853 based on the description of a juvenile specimen (see Froese and Pauly 2008). We have obtained entobdelline monogenean skin parasites from T. meyeni from a range of localities in the western Pacific Ocean, namely Australia (Queensland), Taiwan and Japan. In August 1996, Mr Rod Garner, aquarist at a public aquarium (Under-
Water World, Mooloolaba, Queensland, Australia) found entobdelline monogeneans attached to the tail of $T$. meyeni and sent specimens to us. In September 1996, additional specimens from the dorsal surface of the host were sent by $\mathrm{Mr}$ Garner. In May 2000, a large collection of entobdelline monogeneans was donated by Mr Ming Hui Chen of the National Museum of Marine Biology and Aquarium in Taiwan. The host was identified by Mr Ming Hui Chen as T. melanospila (= T. meyeni; see above), and the parasites were removed by freshwater treatment of an unspecified number of infected stingrays. In June 2003, we acquired 3 specimens of an entobdelline collected by Mr Julian Baggio after freshwater treat- 
ment of a single $T$. meyeni specimen held at a fish-holding facility (Cairns Marine Aquarium Fish, Cairns, Queensland, Australia). This stingray specimen was caught on an inshore reef south-east of Cairns. In addition, Dyer et al. (1989) collected entobdellines identified as Entobdella squamula from T. melanospila (=T. meyeni; see above) from the Okinawa Expo Memorial Park Aquarium in Okinawa, Japan and deposited a single specimen in the United States National Parasite Collection (USNPC). Our preliminary survey of this range of parasites from $T$. meyeni, including specimen USNPC No. 80216 of Dyer et al., revealed specific differences between parasites from some of the different localities and from described species of Neoentobdella Kearn et Whittington, 2005. Furthermore, the detailed comparison that followed promised to throw new light on the function of male copulatory organs in these capsalid monogeneans.

\section{Materials and methods}

Parasites were preserved in 10\% formalin, later stained with Semichon's carmine or left unstained, dehydrated in an ethanol series, cleared in cedarwood oil and mounted in Canada balsam. Whole mounts were examined using a compound microscope equipped with phase contrast optics. Measurements, made using a calibrated ocular micrometer, were confined to unfolded, well-flattened specimens and are presented in micrometres as the mean followed by the range in parentheses and the number of measurements taken. Where measurements are separated by a multiplication sign, the first dimension is length followed by width. Possibly because of suboptimal preservation of some specimens, the boundaries of soft parts (testes, pharynx, haptor) were obscure and the limits of some hard parts (e.g. posterior hamuli) were hard to determine. In these circumstances measurements were not taken or were recorded as approximations. Haptoral terminology for capsalids follows Whittington et al. (2001). Haptor measurements exclude the marginal valve.

Type material of the new taxa is deposited in the following curated collections: The Australian Helminthological Collection, Parasitology Section, The South Australian Museum, North Terrace, Adelaide, South Australia 5000, Australia (SAMA AHC; contact: Leslie Chisholm - chisholm.leslie@saugov.sa. gov.au); Parasitology, Biodiversity Program, Queensland Museum, P.O. Box 3300, South Brisbane, Queensland 4101, Australia (QM; contact: Rob Adlard - RobertAd@qm.qld. gov.au); Parasitic Worms, Department of Zoology, Natural History Museum, Cromwell Road, London SW7 5BD, U.K. (BMNH; contact: Eileen Harris - e.harris@nhm.ac.uk); The United States National Parasite Collection, United States Department of Agriculture, Agricultural Research Service, Building 1180, BARC-East, 10300 Baltimore Avenue, Beltsville, Maryland 20705-2350, U.S.A. (USNPC; contact: Eric Hoberg - ehoberg@anri.barc.usda.gov or Pat Pilitt ppilitt@anri.barc.usda.gov).

\section{Results}

Capsalidae Baird, 1853

Entobdellinae Bychowsky, 1957 (as amended by Kearn and Whittington 2005)

Neoentobdella Kearn and Whittington, 2005

\section{Neoentobdella garneri sp. nov. (Figs 1-4A)}

Type host and locality: Taeniura meyeni Müller et Henle, 1841 (Dasyatidae) (blotched fantail ray). Parasites first noticed in UnderWater World, Mooloolaba, Queensland, Australia in

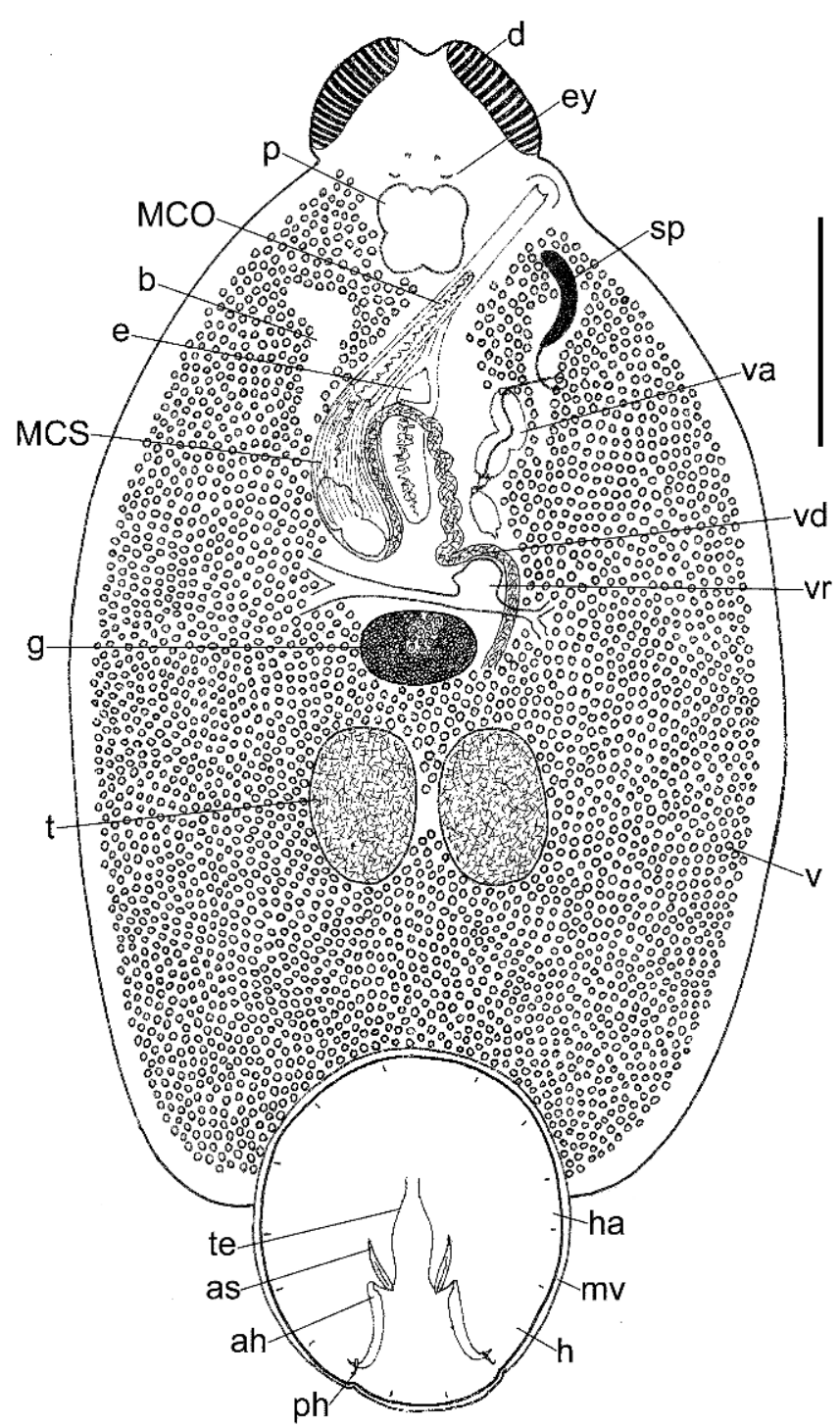

Fig. 1. Neoentobdella garneri sp. nov. Whole animal in ventral view based on holotype and paratypes: ah - anterior hamulus, as - accessory sclerite, b - bladder, d - "diadem", e - egg in ootype, ey - eye spot, $\mathrm{g}$ - germarium, h - hooklet, ha - haptor, MCO - male copulatory organ, MCS - male copulatory sac, mv - marginal valve, $\mathrm{p}$ - pharynx, $\mathrm{ph}$ - posterior hamulus, $\mathrm{sp}$ - spermatophore, $\mathrm{t}-$ testis, te - tendon, $\mathrm{v}$ - vitellarium, va - vagina, vd - vas deferens, vr - vitelline reservoir. Note that the spermatophore capsule lies externally with the spermatophore stalk lodged in the vagina. Scale bar $=1 \mathrm{~mm}$ 
August 1996 on juvenile rays born in a display aquarium. Presumably these monogeneans originated from the mother, but the locality of her capture is unknown to us.

Site on host: Tail and dorsal surface in region of eyes and spiracles (Mr Rod Garner, personal communication).

Origin of name: The species is named in honour of Mr Rod Garner, formerly a curator and aquarist at UnderWater World, Mooloolaba, Queensland, Australia who was responsible for noticing this monogenean species, for bringing it to our attention and for providing specimens.

Holotype: SAMA AHC 29548 (1 whole mount).

Paratypes: SAMA AHC 29549-29554 (6 whole mounts); QM G 230667-G 230671 (5 whole mounts); BMNH 2008. 9.19.1-2008.9.19.2 (2 whole mounts); USNPC 101182 (4 whole mounts).

Description: Based on 18 flattened specimens [16 adults, 1 immature (AHC 29553), 1 similar to latter in size but probably newly mature since contains broken egg appendage (AHC 29552)]. Dimensions based on 16 adults. Total length and maximum breadth: 6684 (4016-9698) (15) × $3402(2527-$ 5023) (15). Haptor length and breadth: 1540 (1164-2271) $(14) \times 1464$ (1203-2106) (14). Length of median haptoral sclerites as follows: accessory sclerites 276 (202-400) (30); anterior hamuli 478 (419-682) (27); posterior hamuli 70 (60-80) (15). Hooklet length 16 (12-19) (17). Granules (probable sclerite material?) adjacent to anterior hamuli rare. Tips of accessory sclerites and anterior hamuli intact. Accessory sclerites slender, slightly curved distally, with characteristic internal structure (Fig. 4A). Tendons in haptor prominent, each one passing around notch at proximal end of accessory sclerite and attaching to proximal (anterior) end of anterior hamulus (Fig. 1). Thin, membranous marginal valve present.

Adhesive pads on anterolateral borders of head region subdivided to form "diadem" (see Llewellyn and Euzet 1964); each pad comprising 21 (16-23) (17) flat, slightly elevated transverse rays (Fig. 1), similar to those of Neoentobdella natans Kearn et Whittington, 2005 but lacking incomplete rays (see Kearn and Whittington 2005). Eye spots present. Large vesicle associated with each posterior eye but not as conspicuous as in N. taiwanensis sp. nov. (see below, Fig. 5). Approximate pharynx dimensions: $425(350-500)(9) \times 400$ (300-540) (9) (estimations only because of indistinct boundaries). In juvenile and newly mature specimen, branched caeca contain brown pigment; small amount of gut pigment in some adults but absent in others; unclear whether caeca unite posteriorly.

General arrangement of reproductive organs and associated ducts as in other entobdellines (see, for example, $N$. natans, as described and illustrated by Kearn and Whittington 2005, figs 2,6) (Figs 1 and 2). Approximate testes dimensions: 560 $(390-870)(22) \times 450(335-600)(21)$ (estimations only because of indistinct boundaries); lacking marginal indentations. Glands of Goto not observed. Male copulatory sac (MCS) conspicuous, long, curving at proximal end towards left side, but not reaching proximal (posterior) chamber of vagina (Figs 1 and 2). At first glance, male copulatory organ (MCO) penis-

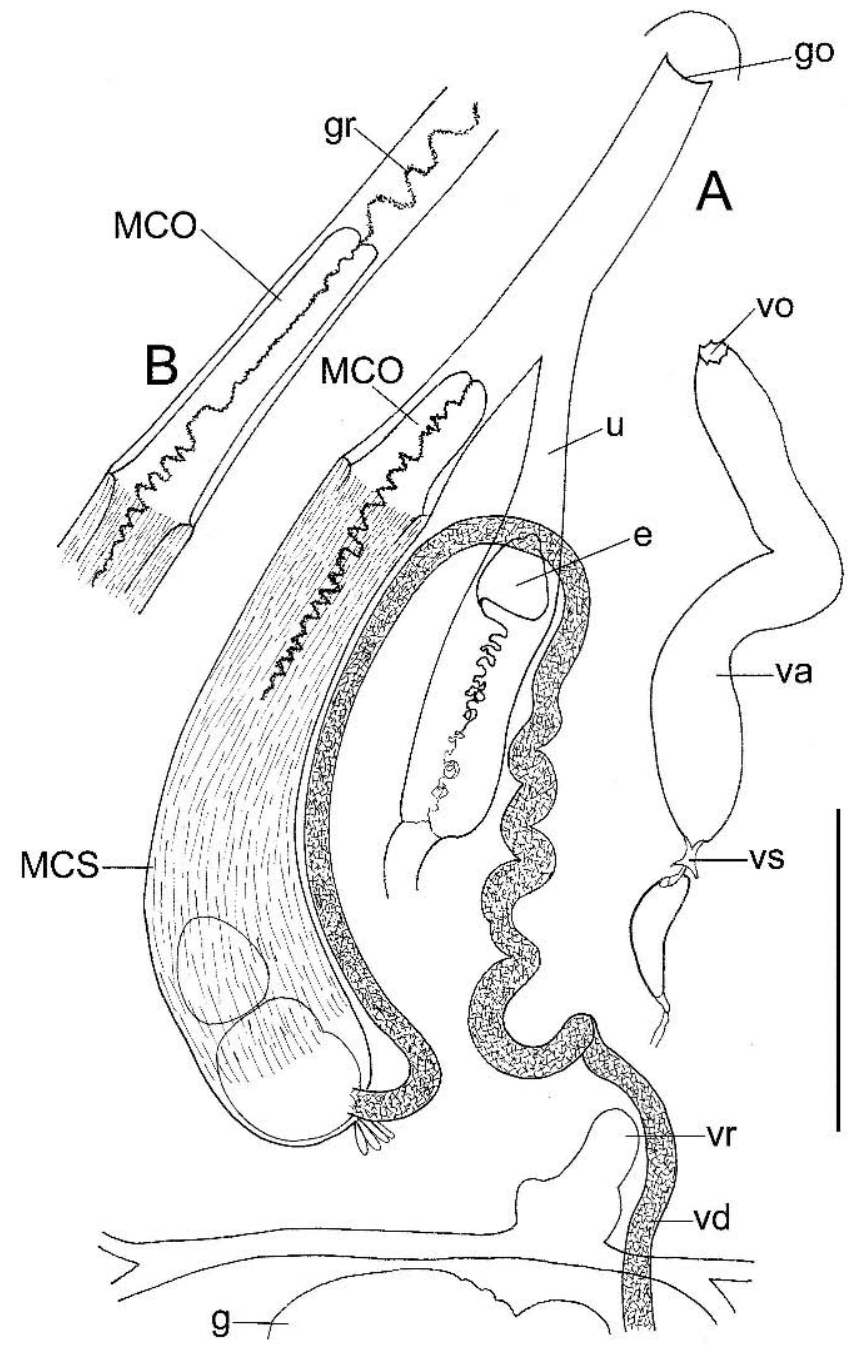

Fig. 2. Enlarged view of reproductive region of Neoentobdella garneri sp. nov. A - Reproductive system showing shorter length of the male copulatory organ (MCO) in an adult specimen. B - MCO of another adult specimen (BMNH 2008.9.19.1) showing its increased length and extrusion of granules (gr). go - common genital opening on protuberance, $\mathrm{u}$ - uterus, vo - vaginal opening, vs - sclerotised funnel in vagina. Other labelling as in Figure 1. Note longitudinal fibres (muscle?) in wall of male copulatory sac (MCS). Scale bar = $500 \mu \mathrm{m}$

like, but survey of range of specimens reveals features typical of cirrus (see Discussion below). Length of MCO lying in MCO canal variable, ranging from 109 to, at least, 500 (cf. Fig. 2A, B). In 3 specimens, MCO protruding through common genital pore (Fig. 3); length of MCO of 2 of these specimens estimated at 1188 and 1375. In MCOs of short or medium length, narrow ejaculatory duct running through MCO follows zigzag or meandering path and typically contains finely granular material, rendering duct highly conspicuous (Fig. 2). In 1 adult parasite, string of granules extruded from opening at distal tip of MCO (BMNH 2008.9.19.1; requires viewing with phase contrast microscope) (Fig. 2B). In parasites with long MCOs, especially those protruding from the genital opening, internal canal straight. MCS with prominent outer sheath of 
closely packed longitudinal fibres arising abruptly at base of $\mathrm{MCO}$ and running in proximal direction to terminate before reaching proximal end of MCS (Fig. 2A). Proximal end of MCS accommodates reservoir with granular contents, most probably structural material for spermatophore; reservoir often 2-chambered. Some specimens with indications that ducts carrying similar granular material enter base of MCS (Fig. 2A), but origin of this material not clear. Vasa efferentia not observed. Vas deferens enters MCS at proximal end but its communication within sac not clear. Narrow ejaculatory duct emerges from distal end of reservoir, enters $\mathrm{MCO}$ and opens at distal tip. Short uterus joins MCO canal, creating common genital canal with opening on conspicuous protuberance on ventral surface near left body margin (Figs 1, 2A and 3). MCO not deflected into uterus in any specimens.

Vagina comprising large distal chamber and smaller proximal chamber (Figs 1 and 2A). Distal chamber a meandering tube with relatively wide lumen, on left side of mid-line, with relatively large opening on ventral surface level with anterior end of ootype. Distal chamber communicates with proximal vaginal chamber via complex sclerotised junction comprising

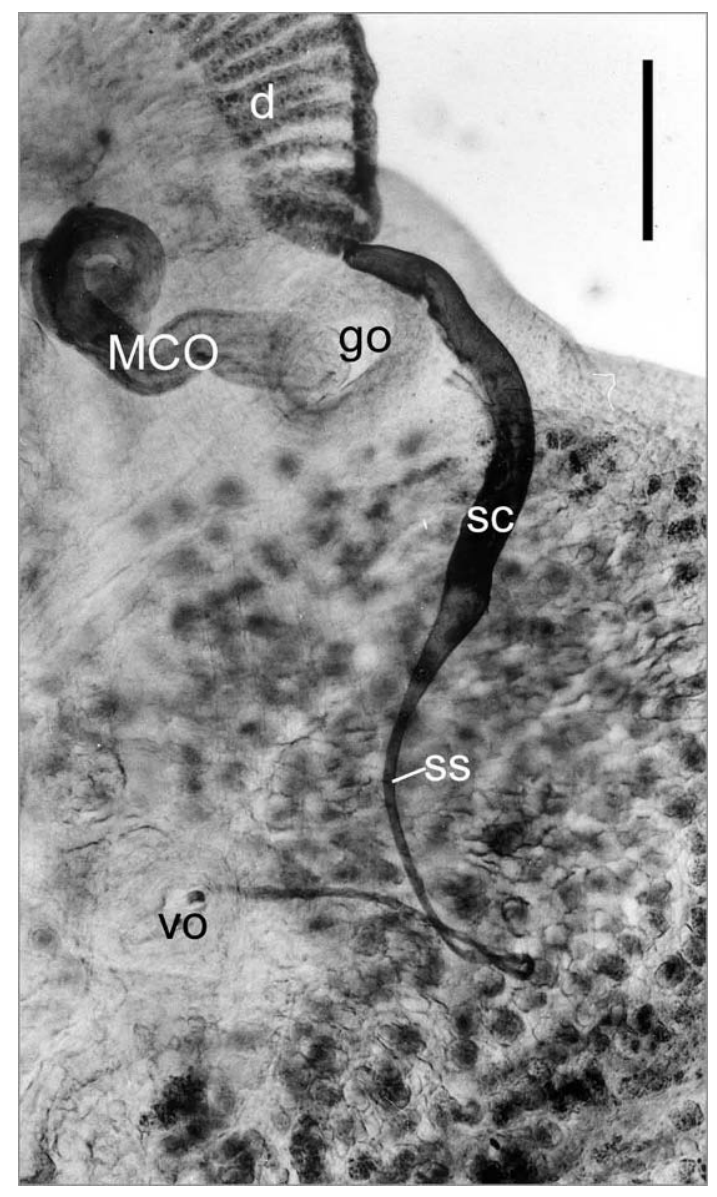

Fig. 3. Spermatophore of Neoentobdella garneri sp. nov. in situ. Ventral view of stained whole mount preparation (AHC 29549) showing d - "diadem", go - common genital opening, $\mathrm{MCO}$ - male copulatory organ, sc - spermatophore capsule, ss - spermatophore stalk, vo - vaginal opening. Scale bar $=200 \mu \mathrm{m}$ funnel leading to short tube which expands and opens into proximal chamber. Narrow exit from proximal end of proximal chamber. In related parasites, vagina opens proximally into vitelline reservoir (as for example in Entobdella stenolepis Kearn, Whittington et Evans-Gowing, 2007; see Kearn et al. 2007), but this was not confirmed in our specimens of $N$. garneri. However in one specimen, proximal end of proximal vaginal chamber in contact with lobe of vitelline reservoir.

In 6 out of 16 adult parasites, spermatophore lodged in vagina (e.g. Figs 1 and 3). Each spermatophore comprises elongated, sausage-shaped capsule, 425-465 long (6) and $38-70$ (6) at widest point and narrow stalk approximately 950 long (6) and 16-24 wide (6) (Figs 1 and 3). Spermatophore anchored in vagina by stalk (Figs 1 and 3), proximal end of which is lodged in sclerotised funnel at proximal end of large distal vaginal chamber (Fig. 1). Distal end of stalk emerges from vaginal pore, hence spermatophore capsule lies outside body (Figs 1 and 3). In 1 specimen, stalk present in vagina but severed at distal end; spermatophore capsule and remaining short length of stalk displaced from vaginal opening. In 2 specimens, capsule missing but stalk still present inside vagina. In 1 specimen with complete stalk and capsule in situ, broken off length of stalk of second spermatophore present in vagina.

Egg present in ootype of some adults. Egg triangular in profile with projecting rounded knob on opercular corner (distal corner with respect to ootype) and long appendage lacking adhesive droplets at proximal corner (Figs 1 and 2A). Side length from opercular corner to appendage root 136 (125142) (5). Appendage estimated to be at least $1.8 \mathrm{~mm}$ long,
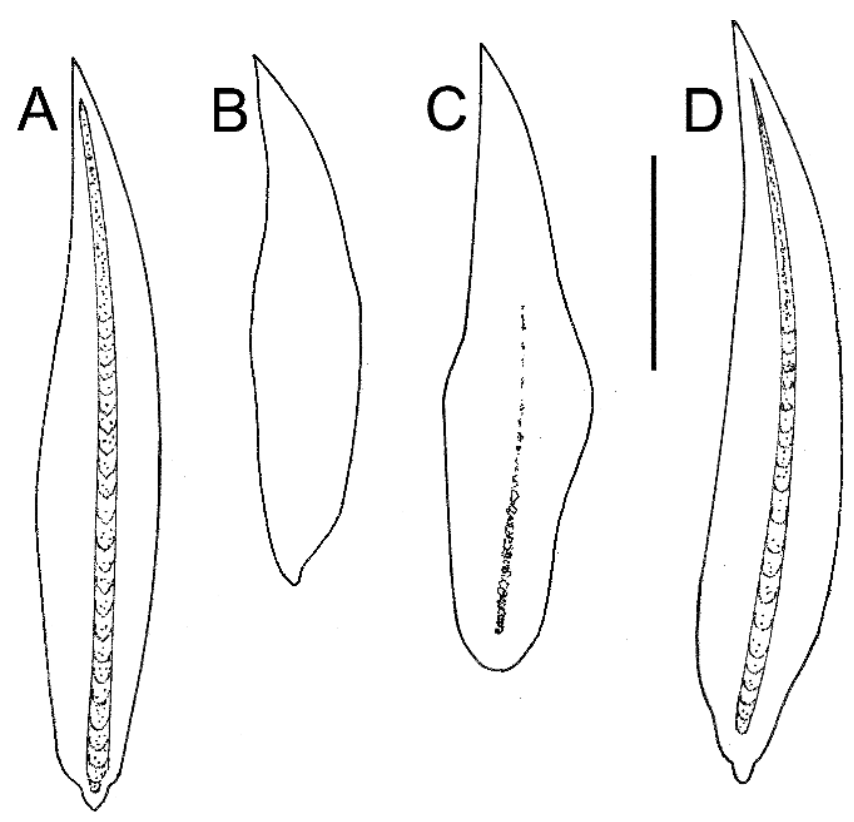

Fig. 4. Accessory sclerites of: A - Neoentobdella garneri sp. nov.; $\mathbf{B}$ and $\mathbf{C}-N$. taiwanensis sp. nov. from Taiwan; $\mathbf{D}-N$. taiwanensis sp. nov. from Cairns (host specimen originally collected from Sudbury Reef, south-east of Cairns, Queensland, Australia), showing development of sclerite core. Scale bar $=100 \mu \mathrm{m}$ 
convoluted and tapering. In 3 specimens, 2, 5 and 20 eggs respectively attached to haptor by appendages looped around peduncle.

Observations on live parasites: Parasites capable of swimming freely with an undulating movement (Rod Garner, personal communication).

Differential diagnosis: With the description of $N$. garneri, there are now 7 species of Neoentobdella: $N$. diadema (Monticelli, 1902) Kearn et Whittington, 2005 (type species), $N$. apiocolpos (Euzet et Maillard, 1967) Kearn et Whittington, 2005, N. australis (Kearn, 1978) Kearn et Whittington, 2005, $N$. bumpusii (Linton, 1901) Kearn et Whittington, 2005, $N$. natans, $N$. parvitesticulata Kearn et Whittington, 2005 and $N$. garneri. Neoentobdella garneri is distinguished from all other species of Neoentobdella, except for the closely similar Neoentobdella taiwanensis sp. nov. (see below), by the long male copulatory sac (MCS), the wall of which contains longitudinal muscle (?) fibres, a male copulatory organ (MCO) which can be long or short (penis/cirrus?; see Discussion) and a spacious 2-chambered vagina with a funnel-shaped sclerite at the junction of its small proximal and large distal chambers. Distinguished from $N$. taiwanensis sp. nov. (see below) by a shorter MCS, not reaching the proximal end of the vagina (cf. Figs 2A and 6) and by a shorter MCO when extended than that of $N$. taiwanensis sp. nov. (approximately $1.38 \mathrm{~mm}$ in $N$. garneri and $>2 \mathrm{~mm}$ in $N$. taiwanensis). Neoentobdella garneri possesses no other embellishments such as a club-shaped (sensory?) structure, grooves/folds and microsclerites in the region of the common genital opening, similar to those present in N. natans (see Kearn and Whittington 2005). Skin parasite of the blotched fantail ray, Taeniura meyeni.

\section{Neoentobdella taiwanensis sp. nov. (Figs 4B-D and 5-7)}

Type host and locality: Taeniura meyeni Müller et Henle, 1841 (Dasyatidae) (blotched fantail ray). From stingrays in display tank of the National Museum of Marine Biology and Aquarium, Taiwan, May 2000. Original source of rays unknown to us.

Other locality: 3 adult specimens from a captive host at Cairns Marine Aquarium Fish, Queensland, Australia, June 2003 . The source of this stingray was Sudbury Reef $\left(17^{\circ} 00^{\prime} \mathrm{S}\right.$, $\left.146^{\circ} 12^{\prime} \mathrm{E}\right)$, an inshore reef south-east of Cairns.

Site on host: Unknown to us. Parasites from stingrays in captivity in Taiwan and from the single captive stingray in Cairns were first noted after freshwater bath treatments.

Origin of name: Named after the country where the parasites were initially collected.

Holotype: AHC 29555 (1 whole mount).

Paratypes: AHC 29556-29559 (4 whole mounts); AHC 29560 (1 whole mount from Sudbury Reef); QM G 230672G 230675 (4 whole mounts); QM G 230676 (1 whole mount from Sudbury Reef); BMNH 2008.9.19.3-2008.9.19.4 (2 whole mounts); USNPC 101183 (1 whole mount); USNPC 101184 (1 whole mount from Sudbury Reef).

Description: Based on 12 flattened specimens from infections at the National Museum of Marine Biology and Aquar- ium, Taiwan ( 9 adults, 3 immature specimens), unless stated otherwise. Dimensions based on 9 adults. Total length and maximum breadth: $7232(5925-8063)(9) \times 4181(2950-5038)$ (9). Haptor length and breadth: $1603(1350-1888)(9) \times 1565$ (1388-1838) (9). Length of median haptoral sclerites as follows: accessory sclerites $250(220-282)(18)$; anterior hamuli 440 (311-486) (18); posterior hamuli 60 (1). Hooklet length 17 (16-18) (2). Tips of anterior hamuli broken in some specimens. Accessory sclerites slender, slightly curved distally; internal structure lacking or greatly reduced in specimens from Taiwan (Fig. 4B, C), but well-developed in specimens from Cairns (Fig. 4D). Tendons in haptor prominent, each one passing around notch at proximal end of accessory sclerite and attaching to proximal (anterior) end of anterior hamulus. Thin membranous marginal valve present. In several specimens, granules resembling sclerite material associated with shafts of

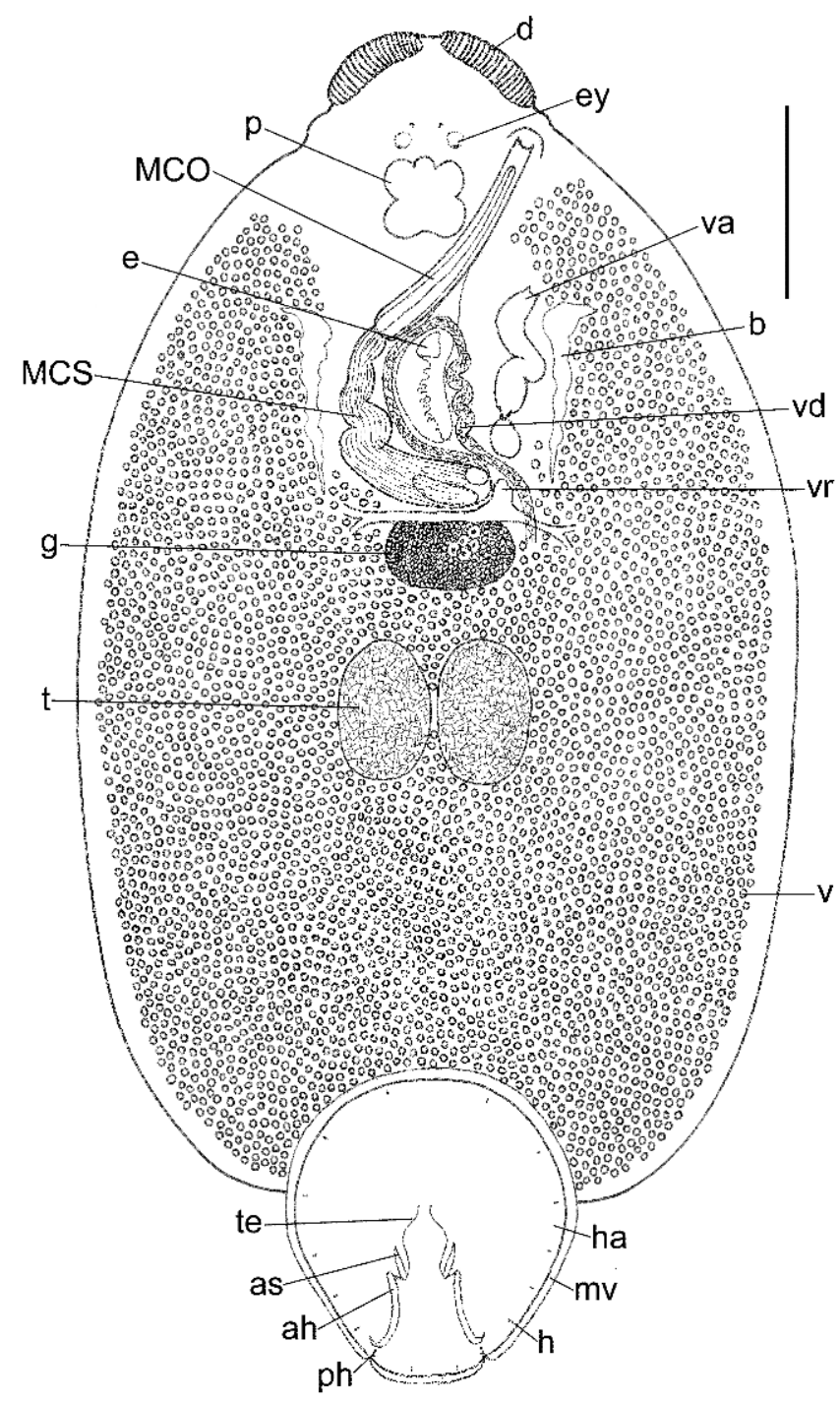

Fig. 5. Neoentobdella taiwanensis sp. nov. Whole animal in ventral view based on holotype and paratypes. Labelling as in Figure 1. No spermatophore present. Scale bar $=1 \mathrm{~mm}$ 
each anterior hamulus. These granules ranged in number from 1 to about 23 per hamulus and ranged in diameter from 6 to 16 . Granules absent in some individuals from Taiwan and in specimens from Cairns.

Adhesive pads on anterolateral borders of head region subdivided to form "diadem" (see Llewellyn and Euzet 1964); each pad comprising 20 (18-21) (8) flat, slightly elevated transverse rays, similar to those of $N$. natans but lacking incomplete rays (see Kearn and Whittington 2005) (Fig. 5). Eye spots present. Each posterior eye spot associated with large clear vesicle, more conspicuous than in N. garneri (see above); pigment granules relatively few, restricted to posterior border of eye vesicle (Fig. 5). Approximate pharynx dimensions $530(440-645)(8) \times 520(415-595)(9)$ (estimations only because of indistinct boundaries). In juveniles, branched caeca contain brown pigment; gut pigment rarely present in adults from Taiwan and absent in adults from Cairns; unclear whether caeca unite posteriorly.

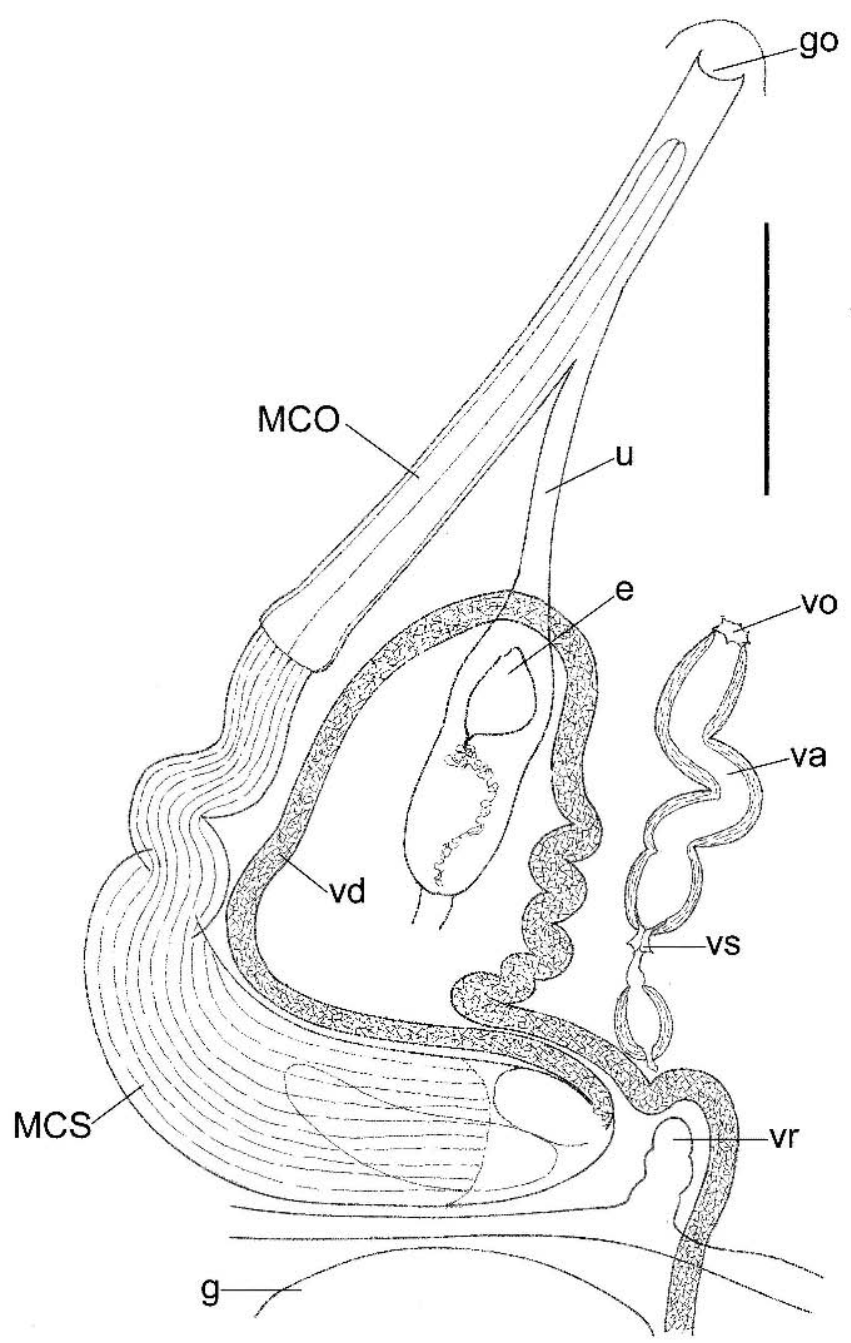

Fig. 6. Enlarged view of reproductive region of Neoentobdella taiwanensis sp. nov. Labelling as in Figures 1 and 2. Note longitudinal fibres (muscle?) in wall of male copulatory sac (MCS). Scale bar= $500 \mu \mathrm{m}$
General arrangement of reproductive organs and associated ducts (Figs 5 and 6) as in N. garneri (see above). MCO long and apparently a penis (but see Discussion below). Organ lying inside MCO canal 1783 long (1504-2136) (4); MCO frequently protruding through common genital pore (e.g. AHC 29556, AHC 29557, BMNH 2008.9.19.3) but in 1 specimen from Taiwan and 2 from Cairns, convoluted MCO enclosed within MCO canal. Short uterus joins MCO canal. In 1 juvenile specimen and 2 adults from Taiwan (e.g. AHC 29559) and 1 adult from Cairns (AHC 29560), MCO appears to be deflected into uterus. Common genital opening ventrally located on conspicuous protuberance near left body margin (Figs 5 and 6). Approximate testes dimensions: 770 (550-900) $(18) \times 675(615-840)(18)$ (estimations only due to indistinct boundaries); lacking marginal indentations. Glands of Goto not observed. Vasa efferentia not seen. Vas deferens convoluted as it runs anteriorly alongside ootype, then bridges anterior region of ootype, turns in posterior direction and follows relatively straight course alongside $\mathrm{MCS}$, entering it at its proximal end (Figs 5 and 6). MCS contains small proximal chamber, possibly receiving vas deferens (requires confirmation) and a larger elongated chamber containing granular material, probably structural material for spermatophore; origin of this material not clear. MCS conspicuous, long, often folded (Fig. 6), curving at proximal end towards left side, almost reaching proximal (posterior) chamber of vagina. MCS with prominent outer sheath of closely packed longitudinal fibres (muscle?) arising abruptly at base of MCO and running in proximal direction to terminate before reaching posterior end of MCS. Abrupt proximal termination of fibres clearly seen in juveniles (Fig. 7). In MCO narrow ejaculatory duct not following zigzag path and lacking granular content.

Vagina comprising large distal and smaller proximal chambers (Figs 5 and 6). Distal chamber a meandering tube, on left side of mid-line, with thick, fibrous, possibly muscular wall, opening on ventral surface anterior to level of ootype via relatively large aperture. Distal chamber communicates with small proximal chamber via complex sclerotised junction comprising funnel leading to short tube which expands and opens into proximal chamber. Wall of proximal chamber thick, fibrous and possibly muscular. Proximal end of small chamber gives rise to narrow duct, most probably communicating with lobe of vitelline reservoir (requires confirmation). In other entobdellines, vagina opens proximally into vitelline reservoir (as, for example, in Entobdella stenolepis, see Kearn et al. 2007), but this was not confirmed in our specimens of $N$. taiwanensis. In 2 adult parasites, vagina contained presumed spermatophore stalk. In 1 specimen, stalk protruded by about 60 from vaginal opening and stretched proximally to end of main vaginal chamber; in other specimen, only short length of stalk remaining at proximal end of main vaginal tube. No spermatophore capsules found. No spermatophore capsules or stalks found in specimens from Cairns.

Egg present in ootype of some adults (Figs 5 and 6). Egg triangular in profile with projecting rounded knob on opercu- 


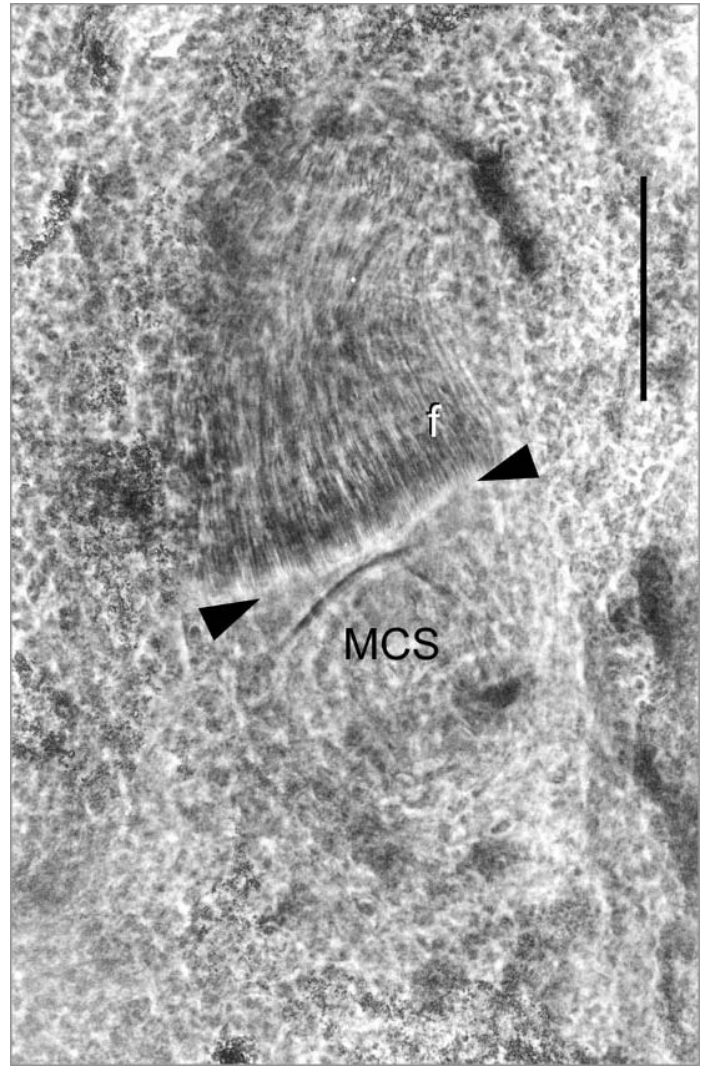

Fig. 7. Phase contrast micrograph of whole mount preparation (QM G 230674) showing proximal end of male copulatory sac (MCS) of immature specimen of Neoentobdella taiwanensis sp. nov. Note fibres (muscle?) (f) terminating abruptly (arrowheads) in MCS wall. Scale bar $=50 \mu \mathrm{m}$

lar corner (distal corner with respect to ootype) and long appendage lacking adhesive droplets at proximal corner. Side length from opercular corner to appendage root 131 (125135) (4). Appendage exceptionally long but coiled and difficult to measure accurately.

Dimensions of 3 adult specimens from Cairns: total length and maximum breadth $8488(8250-8963)(3) \times 4983(4525$ 5450) (3). Haptor length and breadth 2150 (2013-2400) (3) $\times$ 1958 (1588-2225) (3). Length of median haptoral sclerites as follows: accessory sclerites 320 (314-329) (6); anterior hamuli 583 (525-612) (6); posterior hamuli 53 (45-60) (5). Pharynx dimensions $525(502-549)(3) \times 523(502-533)(3)$. Testis dimensions $839(825-863)(6) \times 827(663-1063)(6)$. Anatomically, parasites from Cairns indistinguishable from specimens from Taiwan, with exception of accessory sclerites which possessed a prominent core in Cairns specimens (Fig. 4D).

Differential diagnosis: Distinguished from all other species of Neoentobdella, except for the closely similar $N$. garneri (see above), by the long male copulatory sac (MCS), the wall of which contains longitudinal muscle (?) fibres, the long male copulatory organ (MCO) and the spacious 2-chambered vagina with funnel-shaped sclerite at the junction of its small proximal and large distal chambers. Distinguished from $N$. garneri (see above) by a longer MCS that curves towards the left side of the body and almost reaches the proximal chamber of the vagina and by a longer extended MCO ( $>2 \mathrm{~mm}$ compared with approximately $1.38 \mathrm{~mm}$ in $N$. garneri) (cf. Figs $2 \mathrm{~A}$ and 6). Neoentobdella taiwanensis has no other embellishments in the region of the common genital opening, such as a club-like (sensory?) structure, grooves/folds and microsclerites, similar to those present in N. natans (see Kearn and Whittington 2005). Skin parasite of the blotched fantail ray, Taeniura meyeni.

\section{Other entobdellines reported from Taeniura meyeni}

In 1985, Dyer et al. (1989) examined 2 dead specimens of Taeniura melanospila ( $=$ T. meyeni; see above) from the Expo Aquarium, Montobu-Cho, Okinawa, Japan. Both fishes were described as having "very heavy infestations $(100+$ parasites)" of Entobdella squamula and the deaths of these hosts were attributed to these heavy parasite burdens. One of these fishes, described as "freshly dead" and "covered with monogeneans", was a $34.5 \mathrm{~kg}$ female, $174 \mathrm{~cm}$ in total length with a disc length of $96 \mathrm{~cm}$ and a disc width of $104 \mathrm{~cm}$. Dyer et al. (1989) deposited a single parasite specimen (USNPC No. 80216), which we obtained on loan.

Description: Dimensions of USNPC No. 80216 of Dyer $e t$ al. (1989) as follows. Total length and maximum breadth: $3700 \times 2256$; haptor length and breadth: $1213 \times 1138$; length of accessory sclerites: 200, 195; length of anterior hamuli: 432,439 ; length of posterior hamuli: 72,66 ; pharynx dimensions: $320 \times 250$; dimensions of testes: $325 \times 300,290 \times 235$ (approximations only; borders not clearly defined). No papillae on ventral surface of haptor; 1 accessory sclerite contains prominent internal structure but core of other accessory sclerite less obvious. Anterior adhesive apparatus a "diadem", with adhesive pads bearing 20 and 23 rays, respectively. No external reservoir for male accessory gland secretion, as possessed by Entobdella spp. (see Kearn et al. 2007). MCS long, curving in median direction proximally and terminating close to proximal end of vagina. $\mathrm{MCO}$ also long, projecting from genital opening; in proximal region, narrow ejaculatory duct inside MCO follows prominent zigzag path. No spermatophore or glands of Goto observed.

\section{Discussion}

We have collected and compared entobdelline (capsalid) monogeneans from the skin of the blotched fantail ray (Taeniura meyeni $=T$. melanospila) from widely separated sites in the western Pacific Ocean. This study has revealed that this ray species is parasitised by 2 species of Neoentobdella, differing in significant ways from other members of the genus. Important morphological differences exist between, on the one hand, $N$. garneri and $N$. taiwanensis, which appear to form a cohesive group based on MCO structure and, on the other hand, N. baggioi Whittington et Kearn, in press, N. cribbi 
Whittington et Kearn, in press (see Whittington and Kearn in press), $N$. natans and $N$. parvitesticulata, which form a separate cohesive group based on the presence of embellishments in the region of the common genital opening and other shared features of the reproductive system (vagina, egg and presumed spermatophore morphology). These differences reveal a diversity within species currently assigned to Neoentobdella that may deserve recognition by separate generic status in the future. Such an action, however, requires a comparative morphological study of all Neoentobdella spp. Importantly, a careful and thorough study of the type species, $N$. diadema, is required, preferably combining an investigation of live parasites, preserved whole mounts and sectioned specimens. We intend to embark on such a study when material is forthcoming.

All infected fishes examined in the present study were from public aquaria or fish-holding facilities. It is assumed that the sources of the infections of captive fishes were local to the site of the aquaria but, apart from parasites from Cairns, northern Queensland, Australia, which were known to originate from an inshore reef south-east of Cairns, the precise geographical origins of the other infections are unknown to us. Parasites from an aquarium in Mooloolaba, southern Queensland, Australia were found to be specifically distinct from parasites from an aquarium in Taiwan, and the 2 taxa have been described as $N$. garneri and $N$. taiwanensis, respectively. Parasites collected from a fish-holding facility in Cairns, northern Queensland, were identified as N. taiwanensis. The single parasite collected by Dyer et al. (1989) from T. melanospila ( $=$ T. meyeni) from an aquarium in Okinawa, Japan and deposited in the USNPC (No. 80216) was identified by them as Entobdella squamula. However, this morphological identification is clearly erroneous since the specimen has no haptoral papillae, has distinct "diadem" rays on the head region and lacks an external reservoir for male accessory gland secretion, all of which are features of Neoentobdella (see Kearn and Whittington 2005). The elongated MCO and large MCS of the specimen of Dyer et al. (1989) resemble those of $N$. taiwanensis, but the zigzag appearance of part of the narrow ejaculatory duct was typical of our specimens of $N$. garneri and not observed in any of our specimens of $N$. taiwanensis. However, the specimen of Dyer et al. (1989) is significantly smaller than our specimens of $N$. taiwanensis and folding of the ejaculatory duct may disappear in larger individuals. There is no doubt that the parasite is not E. squamu$l a$ and we identify it tentatively as a specimen of $N$. taiwanensis described herein.

Entobdellines sometimes coexist on the same host individual, as for example Entobdella hippoglossi and E. vanbenedeni on the halibut (Hippoglossus hippoglossus) (see Kearn et al. 2007), but co-occurring infrapopulations of N. garneri and $N$. taiwanensis have not yet been found on T. meyeni.

The MCO of $N$. garneri looks like a penis lying inside a penis canal, which, as it travels distally, is joined by the uterus and opens ventrally via a conspicuous common genital opening (Fig. 2A). However, in the specimens available to us, the length of the "penis" lying inside the "penis canal" varied from as little as 109 to at least 500 and, in 2 specimens in which the organ protruded from the common genital opening, length estimates were 1188 and 1375. Such an increase in length could be achieved by contraction of circular fibres in the "penis" itself, but this would be expected to lead to a greater decrease in the diameter of the organ than we observed. Another feature of the male copulatory apparatus is the sheath of closely spaced longitudinal fibres enclosing the MCS. This sheath extends from the proximal end of the MCO to a level just distal to the end of the MCS. Assuming that these are muscle fibres, then contraction of the sheath would lead to increased pressure in the sac and eversion of the tip of the MCO, producing an increase in length of this organ. In other words, what appears to be a penis may, in fact, be a cirrus. This would explain the variation in length of the male organ observed in our specimens (cf. Fig. 2A, B) and this variation may reflect the degree of contraction of the muscle sheath of the MCS at the time of preservation. This hypothesis on the functional morphology of the MCO of $N$. garneri needs to be confirmed by observations on living parasites.

In N. garneri, MCOs of short or medium length contained a narrow ejaculatory duct that followed a zigzag or meandering path, often made more conspicuous by the presence of fine granular contents (Fig. 2A, B). In parasites with long MCOs, in particular those that protrude from the genital opening, the ejaculatory duct is straight. Since the MCS has a relatively small volume and must accommodate the lengthy retracted and inverted "cirrus", it is to be expected that the ejaculatory duct running through the retracted MCO would be folded. We suggest that as the MCS is squeezed by contraction of the longitudinal fibres in its wall and eversion of the MCO progresses, the copulatory organ is stretched and the folds in the ejaculatory duct are eliminated.

In 1 adult specimen of $N$. garneri (BMNH 2008.9.19.1), some of the granular contents of the ejaculatory duct have been extruded from the opening at the distal tip of the MCO in the form of a string of granules (Fig. 2B). This may be the result of pressure exerted on the parasite to flatten it at the time of preservation, but a similar event may take place during spermatophore implantation in the living animal. The large size of the vaginal lumen is consistent with insertion of the MCO into the vagina during implantation. If the role of the vagina were simply to accommodate the slender stalk of the spermatophore, there would be no need for such a spacious lumen. The granules may be the basis of the spermatophore stalk, the free end of which is implanted at the proximal end of the distal chamber of the vagina, where it may be held in place by the sclerotised funnel (Figs 1 and 2A). We speculate that the spermatophore capsule containing sperm is then released by the spermatophore donor. The evidence we have suggests that this capsule in $N$. garneri does not enter the vagina but is tethered on the outside of the body of the recipient and is held in place by the stalk (Fig. 3). How sperm enters the vagina is not clear. The stalk is tubular and sperm may be able to pass through the narrow stalk lumen 
into the proximal chamber, where it may be stored for a time before entering the female system, most probably via the vitelline reservoir. The sclerotised junction between the distal and proximal vaginal chambers may also serve to prevent reflux of sperm into the distal chamber. There is no evidence that the spermatophore capsule is engulfed by the vagina and ruptured to release its contents.

The basic layout of the reproductive system of $N$. taiwanensis is similar to that of $N$. garneri but with differences in the degree of development of the male copulatory apparatus. In $N$. taiwanensis, the MCS is larger than that of $N$. garneri and is so long that it is often folded and extends in a posterolateral or lateral direction until it almost makes contact with the proximal chamber of the vagina (Figs 5 and 6). The MCO of $N$. taiwanensis lying inside the male canal is also long, often $>1.5 \mathrm{~mm}$ in length and in 1 specimen $>2 \mathrm{~mm}$ in length with the tip projecting from the common genital opening (BMNH 2008.9.19.3). In no adult specimen was the free MCO as short as $109 \mu \mathrm{m}$ as in N. garneri. Like N. garneri, the MCS of $N$. taiwanensis is enclosed in a sheath of longitudinal fibres, originating at the base of the MCO and extending posteriorly almost to the proximal end of the MCS (Fig. 6). In 3 juvenile specimens in which the male copulatory system was developing, the abrupt termination of the fibre sheath at its proximal end was clearly visible (Fig. 7). None of the specimens of $N$. taiwanensis from Taiwan and Cairns possessed a zigzag ejaculatory duct. This may partly reflect the fact that with the MCO fully retracted, the unretracted portion of the organ is still relatively long. Moreover, the MCS has a significantly larger volume and may be large enough to accommodate the retracted portion of the MCO without any folding of the ejaculatory duct.

Although N. taiwanensis has what appears to be a "penis" much greater in length than that of $N$. garneri, the similarities between the 2 parasites in the musculature enclosing the MCS suggest that their reproductive systems are functionally similar. It is possible that their MCOs combine the functions of a "penis" and a "cirrus", with, in N. garneri, the cirrus function predominating and, in N. taiwa nensis, a more equal division of labour. These observations should alert those studying monogeneans to the possibility that what may appear to be a "penis" may have eversion ability and may at least partly function as a "cirrus". These observations are also relevant to evolutionary considerations of capsalid reproductive systems since they suggest that relatively little evolutionary change is required to switch from "penis" to "cirrus" function or vice versa. Thus in the capsalids, the presence of a cirrus, as in Trimusculotrema heronensis (see Whittington and Kearn 2008), and a penis, as in Entobdella spp. (see Kearn et al. 2007), is not necessarily indicative of wide evolutionary divergence.

The vagina of $N$. taiwanensis is similar to that of $N$. garneri. There is a similar sclerotised junction between the distal and proximal chambers and the opening of the vagina on the ventral surface is large and conspicuous. None of our specimens of $N$. taiwanensis carried an intact spermatophore and no spermatophore capsules were found. However, the presence of stalks similar to the spermatophore stalks of $N$. gar$n e r i$ in the vaginae of 2 adult $N$. taiwanensis indicates that spermatophore transfer in these 2 species is similar.

In 2 adult and 1 juvenile $N$. taiwanensis, the MCO appeared to be deflected into the uterus. Thus self-insemination via the uterus may occur, although it is not clear how sperm reaches the germarium, the probable site of fertilisation (see Tappenden et al. 1993), against the flow of traffic involved in egg assembly. In juveniles in which the female system is not yet functional, this would not be a problem. Self-insemination via the vagina is also feasible. Indeed, the MCO of $N$. taiwanensis is probably long enough to reach the proximal end of the vagina of a co-copulant or indeed the proximal end of its own vagina (self-insemination). However, there is no evidence to support this suggestion.

Comparison between $N$. garneri and $N$. taiwanensis revealed features of the haptor that appeared, at first sight, to be useful in distinguishing the 2 species. The most striking of these features was the presence of a conspicuous core running almost the full length of each accessory sclerite in $N$. garneri (Fig. 4A). This core was absent or poorly developed in the specimens of $N$. taiwanensis from Taiwan (Fig. 4B, C). However, the accessory sclerites of all 3 adult specimens of $N$. taiwanensis from Cairns possessed fully developed longitudinal cores (Fig. 4D), as in N. garneri, indicating that this is an unreliable distinguishing feature. In addition, granules that appear to be made of sclerite material located in the haptor close to the anterior hamuli were rare in $N$. garneri but frequently present in $N$. taiwanensis from Taiwan, but the absence of such granules from all 3 specimens of $N$. taiwanensis from Cairns indicated that this feature is also unreliable.

The gut caeca of the immature specimens of both $N$. garneri and $N$. taiwanensis contained brown pigment granules. It is most unlikely that this pigment is haematin derived from host blood, since entobdelline monogeneans feed on host epidermis (Kearn 1998, 1999). A more likely explanation is that the gut pigment of the young parasites is derived from pigment (melanin?) in the host's epidermis and ingested during feeding. Pigment was found in the upper epidermis of the stingray Amphotistius (= Neotrygon; see Froese and Pauly 2008) kuhlii and in the gut of young specimens of Entobdella (=Neoentobdella; see Kearn and Whittington 2005) australis from the stingray's upper surface, but not in an adult from the unpigmented lower surface (Kearn 1979). Adults and juveniles of the monocotylid skin parasite Dendromonocotyle kuhlii from the upper surface of Neotrygon kuhlii also contained abundant pigment in the gut caeca (Kearn 1979). Gut pigment was present in the gut caeca of several adult specimens of Neoentobdella garneri but was rarely encountered in adult $N$. taiwanensis. It is possible that, during development, parasites change their location on the host from an area with pigmented epidermis to one lacking epidermal pigment. However, this cannot be confirmed using our present material, since there is uncertainty about the sites of the immature and mature parasites on the bodies of their hosts. 
Neoentobdella garneri is able to swim freely by means of body undulations. Swimming by body undulation has been observed previously in immature and in mature specimens of $N$. natans and $N$. parvitesticulata (see Kearn and Whittington 1991, 2005) and may be a feature of all Neoentobdella spp., permitting colonisation of new hosts without the need for hosts to make physical contact. The monogenean Gyrodactylus rysavyi (Gyrodactylidae) is also able to swim freely but achieves this by vigorous flexing of the body (El-Naggar et al. 2004).

Acknowledgements. This study would not have been possible without the watchful eyes of Rod Garner (formerly an Aquarist and Curator at UnderWater World, Mooloolaba, Queensland, Australia), Ming Hui Chen, a Research Assistant at the National Museum of Marine Biology and Aquarium, Taiwan and Julian Baggio, Senior Aquarist, Cairns Marine Aquarium Fish, Cairns, Queensland, Australia. We are grateful to these aquarists for their donations of monogeneans. We thank Dr Leslie Chisholm and Dr Vanessa Glennon of the Marine Parasitology Laboratory at The University of Adelaide for specimen preparation and Dr Pat Pilitt (USNPC) for the loan of USNPC No. 80216. Financial support for this study was provided by Australian Research Council (ARC) grant no. DP0556780 (2005-07) awarded to IDW and Professor Steve Donnellan (Evolutionary Biology Unit, South Australian Museum).

\section{References}

Dyer W.G., Williams E.H.Jr., Bunkley Williams L. 1989. Monogeneans from marine fishes of Okinawa, Japan. Proceedings of the Helminthological Society of Washington, 56, 64-68.

El-Naggar M.M., El-Naggar A.A., Kearn G.C. 2004. Swimming in Gyrodactylus rysavyi (Monogenea, Gyrodactylidae) from the Nile catfish, Clarias gariepinus. Acta Parasitologica, 49, 102-107.

Froese R., Pauly D. (Eds.). 2008. FishBase. World Wide Web electronic publication. www.fishbase.org, version (07/2008).

Kearn G.C. 1979. Studies on gut pigment in skin-parasitic monogeneans, with special reference to the monocotylid Dendromonocotyle kuhlii. International Journal for Parasitology, 9, 545-552. DOI: 10.1016/0020-7519(79)90011-0.
Kearn G.C. 1998. Parasitism and the Platyhelminths. Chapman \& Hall, London, U.K., 544 pp.

Kearn G.C. 1999. The survival of monogenean (platyhelminth) parasites on fish skin. Parasitology, 119, S57-S88.

Kearn G.C., Whittington I.D. 1991. Swimming in a sub-adult monogenean of the genus Entobdella. International Journal for Parasitology, 21, 739-741. DOI: 10.1016/0020-7519(91)90 090-T.

Kearn G.C., Whittington I.D. 2005. Neoentobdella gen. nov. for species of Entobdella Blainville in Lamarck, 1818 (Monogenea, Capsalidae, Entobdellinae) from stingray hosts, with descriptions of two new species. Acta Parasitologica, 50, $32-48$.

Kearn G.C., Whittington I.D., Evans-Gowing R. 2007. A revision of Entobdella Blainville in Lamarck, 1818, with special emphasis on the nominal (type) species "Entobdella hippoglossi (Müller, 1776) Blainville, 1818” (Monogenea: Capsalidae: Entobdellinae) from teleost flatfishes, with descriptions of three new species and a new genus. Zootaxa, 1659, 1-54.

Last P.R., Stevens J.D. 1994. Sharks and rays of Australia. CSIRO Division of Fisheries, Australia, 513 pp.

Llewellyn J., Euzet L. 1964. Spermatophores in the monogenean Entobdella diadema Monticelli from the skin of sting-rays, with a note on the taxonomy of the parasite. Parasitology, 54, $337-344$.

Tappenden T., Kearn G.C., Evans-Gowing R. 1993. Fertilization and the functional anatomy of the germarium in the monogenean Entobdella soleae. International Journal for Parasitology, 23, 901-911. DOI: 10.1016/0020-7519(93)90056-5.

Whittington I.D., Kearn G.C. 2008. Trimusculotrema heronensis sp. nov. (Monogenea, Capsalidae) from the skin of the pink whipray Himantura fai (Elasmobranchii, Dasyatidae) from Heron Island, Queensland, Australia. Acta Parasitologica, 53, 251-257. DOI: 10.2478/s11686-008-0044-5.

Whittington I.D, Kearn G.C. Two new species of Neoentobdella (Monogenea, Capsalidae, Entobdellinae) from the skin of Australian stingrays (Dasyatidae). Folia Parasitologica, in press.

Whittington I.D., Deveney M.R., Wyborn S.J. 2001. A revision of Benedenia Diesing, 1858 including a redescription of $B$. sciaenae (van Beneden, 1856) Odhner, 1905 and recognition of Menziesia Gibson, 1976 (Monogenea: Capsalidae). Journal of Natural History, 35, 663-777. DOI: 10.1080/0022293015 2023090 